CHAPTER 10

\title{
Not an Intractable Challenge
}

\section{Geoengineering MSR in ABNJ}

\author{
Karen N. Scott
}

\begin{abstract}
This chapter examines the rules relating to marine scientific research as they apply to marine geoengineering taking place in ABNJ. It will analyse the regime currently evolving under the 1996 London Protocol to the 1972 London (Dumping) Convention, which has been developed to manage ocean fertilization scientific research in the context of the regulation of marine scientific research under the 1982 United Nations Convention on the Law of the Sea (UNCLOS). As the Southern Ocean has been the location for several ocean fertilization experiments to date, the relevant rules under the 1991 Environmental Protocol to the 1959 Antarctic Treaty, particularly environmental impact assessments, will also be assessed. This chapter briefly assesses the relationship between these regimes and the future Agreement under UNCLOS on the conservation and sustainable use of biodiversity and concludes that this Agreement - whatever the outcome of the negotiations-will not operate as a panacea for managing activities in ABNJ. With respect to geoengineering MSR, the potential 'solution' to managing its risks lies in supporting and implementing the existing regime.
\end{abstract}

\section{Keywords}

geoengineering - environmental impact assessment - marine scientific research - areas beyond national jurisidiction

\section{Introduction}

Managing and mitigating the impacts of activities taking place beyond the jurisdiction of states comprises a significant (but hopefully not intractable) challenge for the negotiators of a legally binding agreement under the United Nations Convention on the Law of the Sea on the conservation and sustainable 
use of marine biodiversity. ${ }^{1}$ While negotiations are far from being concluded, delegates have broadly agreed on three tools to manage the impacts of activities taking place beyond national jurisdiction: the application of general environmental principles (such as precaution and an ecosystem approach); area-based management and the regulation of activities taking place within protected areas; and environmental impact assessment. ${ }^{2}$ All three tools are already used to a greater or lesser extent under existing instruments currently of application to areas beyond national jurisdiction $(\mathrm{ABNJ})$. The most significant activities taking place in $\mathrm{ABNJ}$ to date-shipping, fishing and, to a lesser extent, mining - are all regulated under existing regimes and are unlikely to be significantly impacted by the ввNJ Agreement. ${ }^{3}$ Less common activities, on the other hand, may well be subject to controls under the new Agreement.

This chapter explores one such activity, geoengineering scientific research, and examines the recent and emerging regime at both the international and the regional levels designed to regulate this controversial use of the ocean commons. It will focus on the law of the sea as developed under both the 1982 United Nations Convention on the Law of the Sea (UNCLOS) 4 and the 1996 Protocol $^{5}$ to the 1972 London Convention ${ }^{6}$ as it relates to regulating geoengineering marine scientific research. In particular, this chapter will highlight the various underlying tensions associated with managing geoengineering as a scientific research issue. In light of the location of a number of geoengineering

1 A Formal preparatory committee to develop a binding instrument was established in 2016 pursuant to General Assembly Resolution 69/292, Development of an international legally binding instrument under the United Nations Convention on the Law of the Sea on the conservation and sustainable use of marine biological diversity of areas beyond national jurisdiction, A/RES/69/292 (19 June 2015) and formal negotiations were instituted by General Assembly Resolution 72/249, International legally binding instrument under the United Nations Convention on the Law of the Sea on the conservation and sustainable use of marine biological diversity of areas beyond national jurisdiction Statement of financial implications, A/RES/72/249 (24 December 2017). Both available at undocs.org.

2 At the time of writing a revised draft text of an agreement under the United Nations Convention on the Law of the Sea on the conservation and sustainable use of marine biological diversity of areas beyond national jurisdiction is due to be discussed at the fourth negotiating session (New York, 23 March-3 April 202O). See A/CONF.232/2020/3 (distribued 18 November 2019) available at: https://undocs.org/en/a/conf.232/2020/3 (hereinafter, вBNJ March 2020 Draft Text).

3 It has been agreed that the BвNJ Agreement will not undermine existing instruments although at the time of writing the text of this provision (currently, Article 4) has not been agreed. See ibid.

41982 United Nations Convention on the Law of the Sea (UNCLOS) 21 (1982) ILM 1261.

51996 Protocol to the 1972 London Dumping Convention 36 (1997) ILM 7.

61972 Convention on the Prevention of Marine Pollution by Dumping of Wastes and other Matter (London) 11 (1972) ILM 1974. 
experiments in the Southern Ocean, and the fact that this region accounts for 40 percent of the global uptake of anthropogenic carbon dioxide, ${ }^{7}$ this paper will also examine the controls of scientific research developed under the 1959 Antarctic Treaty ${ }^{8}$ and the 1991 Environmental Protocol to the Antarctic Treaty. ${ }^{9}$ This chapter will critique the efficacy of the evolving regulatory framework for geoengineering research and assess its fitness for purpose in light of the risks this activity poses. It will conclude with some observations on the relationship between the geoengineering MSR regime and the BBNJ Agreement.

\section{Geoengineering and the Oceans}

The oceans and the atmosphere are intimately linked through natural processes. The oceans have sequestered approximately 25 percent of all anthropogenic carbon dioxide since $1750,{ }^{10}$ and, without this service, atmospheric concentration of carbon dioxide would be approximately 55ppm higher than current observations. ${ }^{11}$ This is a service with a significant cost, however..$^{12}$ The upper ocean (above 70om) has warmed by an average of between $0.11^{\circ}$ and $0.13^{\circ} \mathrm{C}$ per decade between 1971 and 2010, a trend which likely began in the late nineteenth century. ${ }^{13} \mathrm{~A}$ warmer ocean (in addition to melting ice-shelves and glaciers) has resulted in a rise in an average sea level of $0.19 \mathrm{~m}$ between 1901 and 2010. ${ }^{14}$ Alteration in ocean salinity levels have led to changes in water circulation and ocean biochemistry. The $\mathrm{pH}$ level of the oceans has decreased ${ }^{15}$ and it is estimated

$7 \quad$ Peter Landschützer, Nicolas Gruber, F. Alexander Humann et al., 'The reinvigoration of the Southern Ocean carbon sink' 349 (11 September 2015), Science $1221-1224$ at 1221.

81959 Antarctic Treaty 402 UNTS 71.

91991 Protocol to the Antarctic Treaty on Environmental Protection 30 (1991) ILM 1461.

10 Pierre Friedlingstein, 'Carbon cycle feedbacks and future climate change' (2015), 373 Philosophical Transactions R. Soc 20140421.

11 Christopher L. Sabine, Richard A. Feely and Nicolas Gruber et al., 'The Oceanic Sink for Anthropogenic $\mathrm{CO}_{2}$ ' 305 (16 July 2004), Science 367 at 370 .

12 SeegenerallyEdward H. Allison and Hannah R. Bassett, 'Climate change in the oceans: Human impacts and responses' 350 (13 November 2015), Science 778; Lisa A. Levin and Nadine Le Bris, 'The deep ocean under climate change' 350 (13 November 2015) Science 766; and Toby Tyrrell, 'Anthropogenic Modification of the oceans' 369 (2011), Phil. Trans. R. A 887.

13 M. Rhein et al., 'Observations: Ocean' in T.F. Stocker (ed.) et al., Climate Change 2or3: The Physical Science Basis. Contribution of Working Group I to the Fifth Assessment Report of the Intergovernmental Panel on Climate Change (Cambridge University Press 2013), 257 (hereinafter, IPCC 5th Assessment Report). See also John M. Lyman, Simon A. Good, Victor V. Gouretski et al., 'Robust warming of the global upper ocean' (2010), 465 Nature 334.

14 IPCC 5th Assessment Report, above n 4, at 258.

15 IPCC 5th Assessment Report, ibid., at 257-9. 
that ocean acidity could increase 150 percent by $2050 .{ }^{16}$ Ocean acidification constitutes a major threat to calcifying marine organisms, including coral, in addition to coastal defences, ${ }^{17}$ and is likely to prove a particular threat to the Arctic Ocean ecosystem. ${ }^{18}$ More generally however, climate change has already affected the distribution and abundance of phytoplankton ${ }^{19}$ and fish. ${ }^{20}$

Some scientists and policy-makers however, regard the oceans as a solution to, rather than simply a victim of, climate change. By artificially enhancing the natural processes whereby carbon dioxide is naturally transferred from the surface to the deep ocean by means of the biological and solubility pumps, scientists have posited that the oceans can be exploited as a climate change mitigation measure. The artificial nature of the enhancement characterises this activity as 'geoengineering', which is commonly defined to mean the deliberate, large scale manipulation of environmental systems for the purposes of climate change mitigation. ${ }^{21}$ As a technology and indeed a science in its early stages of development, it is unsurprising that to date the initial regulatory focus has been on managing geoengineering research-related activities.

Geoengineering techniques are designed either to remove $\mathrm{CO}_{2}$ from the atmosphere or to deflect or reflect solar radiation from the earth. Technologies aimed at atmospheric carbon dioxide removal (CDR) focus on enhancing natural processes that normally perform this function. $\mathrm{CDR}$ includes afforestation or reforestation, ${ }^{22}$ soil-carbon sequestration, ${ }^{23}$ the use of $\mathrm{CO}_{2}$ absorbing

16 Ibid.

17 Scott C. Doney et al., 'Ocean Acidification: A Critical Emerging Problem for the Oceans' (2009), 22 Oceanography 16, at 18.

18 C.P.D. Brussard, A.A.M. Noordeloos, H. Witte et al., 'Arctic microbial community dynamics influenced by elevated $\mathrm{CO}_{2}$ levels' (2013) 10 Biogeosciences 719 .

19 Séverine Alvain, Corinne Le Quéré, Laurent Bopp et al., 'Rapid climatic driven shifts of diatoms at high latitudes' (2013), 132 Remote Sensing of Environment 195.

$20 \quad$ M.J. Salinger, 'A brief introduction to the issue of climate and marine fisheries' (2013), 119 Climatic Change 23.

21 David W. Keith, 'Geoengineering the Climate: History and Prospect' (2000), 25 Annual Review of Energy and the Environment 245, at 247.

22 See Josep G. Canadell and Michael R. Raupach, 'Managing Forests for Climate Change Mitigation' (2008) 320 Science 1456; Leonard Ornstein, Igor Aleinov and David Rind, 'Irrigated afforestation of the Sahara and Australian Outback to end global warming' (2009), 97 Climatic Change 409; Kenneth R. Richards and Carrie Stokes, 'A Review of Forest Carbon Sequestration Cost Strategies: A Dozen Years of Research' (2004), 63 Climatic Change 1; Brent Sohngen, 'Forestry Carbon Sequestration' in Bjørn Lomborg, Smart Solutions to Climate Change: Comparing Costs and Benefits (CUP 2010), 114; Massimo Tavoni, Brent Sohngen and Valentina Bosetti, 'Forestry and the carbon market response to stabilize climate' (2007), 35 Energy Policy 5346.

23 See Raj K. Shrestha and Rattan Lal, 'Ecosystem carbon budgeting and soil carbon sequestration in reclaimed mine soil' (2006), 32 Environment International 781. 
algae on building surfaces ${ }^{24}$ and even the capture and storage of atmospheric $\mathrm{CO}_{2}$ by artificial 'trees.' ${ }^{25}$ Solar radiation management (SRM) techniques by contrast, do not attempt to alter the balance of carbon dioxide between the atmosphere, biosphere and hydrosphere but, instead, are designed to offset increases in temperature caused by climate change through management of solar radiation. Such techniques include urban albedo enhancement, ${ }^{26}$ marine cloud brightening ${ }^{27}$ and whitening the stratosphere. ${ }^{28}$ Beyond reflecting sunlight back into space, the most radical ideas associated with SRM seek to actually deflect sunlight from the Earth through the placement of strategic mirrors between the earth and the sun or in orbit around the earth. ${ }^{29}$

24 Eduardo Jacob-Lobes, Carols Henrique Gimenes Scoparo and Telma Teixeira Franco, 'Rates of $\mathrm{CO}_{2}$ removal by Aphanothece microscopic Nägeli in tubular photobioreactors' (2008), 47 Chemical Engineering and Processing 1365.

25 K.S. Lackner, 'Capture of carbon dioxide from ambient air' (2009), 176 The European Physical Journal, Special Topics 93.

26 Hashem Akbari, Surabi Menon and Arthur Rosenfeld, 'Global cooling: increasing world-wide urban albedos to offset $\mathrm{CO}_{2}$ ' (2009), 94 Climatic Change 275, at 277 and Robert M. Hamwey, 'Active Amplification of the Terrestrial Albedo to Mitigate Climate Change: An Exploratory Study' (2007), 12 Mitigation and Adaptation Strategies for Global Change 419 .

27 John Latham et al., 'Global temperature stabilization via controlled albedo enhancement of low-level maritime clouds' (2008), 366 Phil. Trans. R. Soc. A 3969; Stephen Salter, Graham Sortino and John Latham, 'Sea-going hardware for the cloud albedo method of reversing global warming' (2008), 366 Phil. Trans. R. Soc. A 3989.

28 P. J. Crutzen, 'Albedo Enhancement by Stratospheric Sulfur Injections: A Contribution to Resolve a Policy Dilemma?' (2006), 77 Climatic Change 211; Robert E. Dickinson, 'Climate Engineering: A Review of Aerosol Approaches to Changing the Global Energy Balance' (1996), 33 Climatic Change 279; Yu A. Izrael, 'Field Experiment on Studying Solar Radiation Passing through Aerosol Layers' (2009) 34 Russian Meterology and Hydrology 265; Philip $\mathrm{J}$. Rasch et al., 'An overview of geoengineering of climate using stratospheric sulphate aerosols' (2008), 366 Phil. Trans. R. Soc. A 4007; Alan Robock, Luke Oman and Georgiy L. Stenchikov, 'Regional climate responses to geoengineering with tropical and Arctic $\mathrm{SO}_{2}$ injections' (2008), 113Journal of Geophysical Research D16101; A.F. Tuck, et al., 'On geoengineering with sulphate aerosols in the tropical upper troposphere and lower stratosphere' (2008), 9o Climatic Change 315.

29 See Roger Angel, 'Feasibility of cooling the Earth with a cloud of small spacecraft near the inner Legrange point (L1)' (2006) 103(46), PNAS 17184; James Early, 'Space-based Solar Shield to Offset Greenhouse Effect' (1989),42 Journal of the British Planetary Society 567; Takanobu Kosugi, 'Role of sunshades in space as a climate control option' (2010) 67 Acta Astronautica 241; D. J. Lunt et al., “"Sunshade World”: A fully coupled CGM evaluation of the climatic impacts of geoengineering' (2008) 35 Geophysical Research Letters L12710; C.R. McInnes, 'Space-based geoengineering: challenges and requirements' (2010), 224(3) Proceedings of the Institute of Mechanical Engineers, Part C: Journal of Mechanical Engineering Science 571; Jerome Pearson, John Oldson and Eugene Levin, 'Earth rings for planetary environment control' (2006), 58 Acta Astronautica 44. 
Given the ocean's role as a natural sink for carbon dioxide, it is unsurprising that marine geoengineering has largely focused on CDR rather than SRM. ${ }^{30}$ The CDR technique that has been subject to greatest scientific and regulatory focus to date has been termed 'ocean fertilization'. This technique, as its nomenclature implies, seeks to fertilize ${ }^{31}$ those parts of the ocean-such as the Southern Ocean and the Equatorial Pacific - that are relatively unproductive owing to a relative dearth of nutrients. ${ }^{32}$ This is to stimulate biological productivity and enhance the ocean's biological pump whereby carbon dioxide is transferred from the surface to the deep ocean by means of phytoplankton and sequestered for hundreds if not thousands of years. ${ }^{33}$ The basic hypothesis of ocean fertilization has been proven in that surface levels of carbon dioxide are temporarily reduced as a consequence of artificial fertilization with iron or other nutrients. ${ }^{34}$ However, whether ocean fertilization constitutes a viable climate change mitigation measure is far from clear. Although thirteen official ocean experiments have taken place to date there is no consensus on how long the carbon dioxide is sequestered ${ }^{35}$ and how extensive the fertilized

30 It has nevertheless been suggested that the albedo of the ocean's surface may be enhanced through the creation of reflective microbubbles in the sea. See Russell Seitz, 'Bright water: hydrosols, water conservation and climate change' (2011), ${ }_{105}$ Climatic Change 365 . The most commonly suggested fertilizer is iron but other options include volcanic ash, phosphate and urea. See Svend Duggen, P. Croot, Ulrike Schacht et al., 'Subduction zone volcanic ash can fertilize the surface ocean and stimulate phytoplankton growth: Evidence from biogeochemical experiments and satellite data,' (2007), 34 Geophysical Research Letters, Lo1612; Richard S. Lampitt, E.P. Achterberg, T.E. Anderson et al., 'Ocean fertilization: a potential means of geoengineering?' (2008) 366 Philosophical Transactions of the Royal Society A, 3,919, 3,923; and Julia Mayo-Ramsay, 'Environmental, legal and social implications of ocean urea fertilization: Sulu Sea example,' (2010) 34 Marine Policy 831. H. J. W. de Baar and P. W. Boyd, 'The Role of Iron in Plankton Ecology and Carbon Dioxide Transfer of the Global Oceans' in Roger B. Hansen et al. (eds.) The Changing Ocean Carbon Cycle: A Midterm Synthesis of the Joint Global Ocean Flux Study (CUP 200o) 61, 107; Robert A. Duce and Neil W. Tindale, 'Atmospheric Transport of Iron and Its Deposition in the Ocean' (1991), 36 Limnology \& Oceanography 1715 .

33 John H. Martin, 'Glacial-Interglacial $\mathrm{CO}_{2}$ Change: The Iron Hypothesis,' (1990), 5 Paleoceanography 1. See also, Nicolas Cassar et al., 'The Southern Ocean Biological Response to Aeolian Iron Deposition,' (2007), 317 Science 1067 and P.W. Boyd, J. Jickells, C.S. Law et al., 'Mesoscale Iron Enrichment Experiments 1993-2005: Synthesis and Future Directions,' (2007), 315 Science (2007), 315612.

34 See George A. Wolf, David S.M. Billett, Brian J. Bett et al., 'The effects of Natural Iron Fertilization on Deep-Sea Ecology: The Crozet Plateau, Southern Indian ocean' (2010), 6(6) PLoS One e29697 and Philip Williamson, Douglas W.R. Wallace, Cliff Law et al., 'Ocean Fertilization for geoengineering: A review of effectiveness, environmental impacts and emerging governance' (2012), 9o Process Safety and Environmental Protection 475.

35 S. Blain, 'Effect of Natural Iron Fertilization on Carbon Sequestration in the Southern Ocean' (2007) 446 Nature 1070; P. Boyd et al., 'A Mesocale Phytoplankton Bloom in the 
area must be for the technique to constitute a viable climate change mitigation measure. ${ }^{36}$ Moreover, there are concerns as to the unintended consequences of artificial fertilization including oxygen depletion and ocean acidification, ${ }^{37}$ impacts on the food chain, ${ }^{38}$ introduction of toxic algae ${ }^{39}$ and even the exacerbation of climate change through the release of greenhouse gases including methane and nitrous oxide. ${ }^{40}$

In addition to the artificial introduction of fertilizer to the oceans to stimulate biological productivity, other geoengineering techniques include the artificial transfer of natural fertilizers and nutrients from the deep ocean to the surface by means of vertical pipes ${ }^{41}$ the storage of carbon dioxide in artificially created/enhanced macroalgal forests (including kelp and seaweeds) ${ }^{42}$ and even the disposal of baled crop residues in the deep ocean. ${ }^{43}$ Alternative options seek to enhance the solubility pump through increasing ocean alkalinity by artificially adding limestone powder or soda ash to the oceans, a technique known as 'weathering'.44 A positive impact of weathering is that an increase in ocean alkalinity potentially reduces the effects of ocean acidification. ${ }^{45}$

Polar Southern Ocean Stimulated by Iron Fertilization' (2000), 407 Nature 695; K. Caldeira and P. Duffy, 'The Role of the Southern Ocean in Uptake and Storage of Anthropogenic Carbon Dioxide' (2000), 287 Science 620.

36 K. Buesseler et al., 'The Effects of Iron Fertilization on Carbon Sequestration in the Southern Ocean' (2004) 304 Science 417.

37 Phillip Williamson, Douglas W. R. Wallace, Cliff Law et al., op cit. n. 31, 480-482. See also H. Damon Matthews et al., 'Sensitivity of ocean acidification to geoengineered climate stabilization' (2009), 36 Geophysical Research Letters L10706 doi: 10.1029/2009/GLo37488.

38 A. Strong, 'Ocean fertilization: time to move on' (2009), 461 Nature 347.

39 Q. Schiermeier, 'The Oresmen' (2003), 421 Nature 109, 110.

40 J.Furhman and D. Capone, 'Possible Biogeochemical Consequences of Ocean Fertilization' (1991), 36 Limnology \& Oceanography 1951; M. Lawrence, 'Side-effects of Ocean Iron Fertilization' (2002), 297 Science 1993.

41 See J. Lovelock and C. Rapley, 'Ocean pipes could help the Earth to cure itself' (2007), 449 Nature 403; A Yool et al., 'Low efficiency of nutrient translocation for enhancing oceanic uptake of carbon dioxide' (2009), 114 Journal of Geophysical Research 114.

42 Antione de Ramon N'Yeurt, David P. Chynoweth, Mark E. Capron et al., 'Negative carbon via Ocean Afforestation' (2012), 9o Process Safety and Environmental Protection 467.

43 S. Strand and G. Benford, 'Ocean Sequestration of Crop Residue Carbon: Recycling Fossil Fuel Carbon Back to Deep Sediments' (2009), 43 Environ. Sci. Technol.10o1.

44 L.D.D. Harvey, 'Mitigating the atmospheric $\mathrm{CO}_{2}$ increase and ocean acidification by adding limestone powder to upwelling regions' (2008), 113 Journal of Geophysical Research Co4028; Haroon S. Kheshgi, 'Sequestering Atmospheric Carbon Dioxide by Increasing Ocean Alkalinity' (1995), 20 Energy 915.

45 Jennie C. Stephens and David W. Keith, 'Assessing geochemical carbon management' (2008) 9o Climatic Change 217, at 228. 
What is apparent from the scientific literature to date is that all proposed techniques are at the research stage with most subject to desk-top trials only. The extent to which field trials can and should take place very much depends on the freedoms and constraints associated with scientific research at sea as well as the ethics of research itself. ${ }^{46}$

\section{Defining Marine Scientific Research}

Marine scientific research (MSR) is officially designated a freedom of the high seas by Article $87(1)(\mathrm{f})$ of UNCLOS, and Article 238 confirms that "all States, irrespective of their geographical location, and competent international organizations have the right to conduct marine scientific research subject to the rights and duties of other States as provided for in this Convention." Those rights and duties include those set out in Parts VI, XII and XIII of UNCLOS in addition to the general duty of 'due regard' to the interests of other states. ${ }^{47}$ Notably however, UNCLOs fails to define the term 'marine scientific research' and this omission was deliberate, a definition being deemed "unnecessary" under the 1977 Informal Composite Negotiating Text. ${ }^{48}$ Nevertheless, during the UNCLOS III negotiations, several definitions of MSR were proposed, debated and ultimately, rejected. For example, in the 1973 negotiating round, marine scientific research was defined to comprise: ${ }^{49}$

... any fundamental or applied research and related experimental work, conducted by States and their juridical and physical persons, as well as by international organizations, which does not aim directly at industrial exploitation but is designed to obtain knowledge of all aspects of the natural processes and phenomena occurring in the ocean space, on the seabed and subsoil thereof, which is necessary for the peaceful activity of States for the further development of navigation and other forms of utilization of the sea and also utilization of the airspace above the world ocean.

46 See generally Karen N. Scott, "Engineering and the "Mis-Anthropocene": International Law, Ethics and Geoengineering' 29 (2015), Ocean Yearbook 61-84.

$47 \quad 1982$ UnCLOS, Article $87(1)$ (f) and $87(2)$.

48 Patricia Birnie, 'Law of the Sea and Ocean Resources: Implications for Marine Scientific Research' 10 (1995), International Journal of Marine and Coastal Law 229, at 242.

49 Committee on the Peaceful Uses of the Seabed and the Ocean Floor beyond the Limits of National Jurisdiction, vol. 8, Subcommittee III, A/AC.138/SC.III/L.31 (Bulgaria, Poland, Ukrainian SSR and USSR), Articles 1 and 2. 
This definition of research expressly included what today is described as 'pure' and 'applied' research but nevertheless excluded research aimed 'directly at industrial exploitation. The negotiators further broadened this definition the following year in their development of draft Article 1:50

(a) Marine Scientific Research is any study or investigation of the marine environment and experiments related thereto; (b) Marine Scientific Research is of such a nature as to preclude any clear or precise distinction between pure scientific research and industrial or other research conducted with a view to commercial exploitation or military use.

Some states expressed concern over the expansive definition and subsequent debates focused on whether research associated with the immediate exploitation of resources should be similarly treated to research designed to increase knowledge..$^{51}$ Later definitions attempted to constrain the definition of scientific research to activities designed to increase humankind's knowledge. In 1975, MSR was defined as "any study of, or related experimental work in, the marine environment that is designed to increase man's knowledge and is conducted for peaceful purposes"52 or alternatively "... any study and related experimental work conducted in the marine environment designed to increase mankind's knowledge thereof." 53 This definition was minimally adapted and included in the 1976 Informal Single Negotiating Text as "any study or related environmental work designed to increase mankind's knowledge of the marine environment."54 The definition undoubtedly covered pure scientific research but was ambiguous as to whether it included applied scientific research.

50 Official Records of the Third United Nations Conference on the Law of the Sea, vol. III (United Nations publication, Sales No. E.75.V.5), Trinidad and Tobago: draft articles on marine scientific research, Article 1, paras. (a) and (b), p. 252.

51 UN, Division for Oceans and the Law of the Sea, The Law of the Sea. Marine Scientific Research: A revised guide to the implementation of the relevant provisions of the United Nations Convention on the Law of the Sea (UN New York, 2010) 5 .

52 Official Records of the Third United Nations Conference on the Law of the Sea, vol. IV (United Nations publication, Sales No. E.75.V.10), Bulgaria, Byelorussian Soviet Socialist Republic, Czechoslovakia, German Democratic Republic, Hungary, Mongolia, Poland, Ukrainian Soviet Socialist Republic and Union of Soviet Socialist Republics: draft articles on marine scientific research, Articles 1 and 2, para. 4.

53 Ibid., Colombia, El Salvador, Mexico and Nigeria: draft arts. on marine scientific research, Articles 1 and 2.

54 Official Records of the Third United Nations Conference on the Law of the Sea vol. v (United Nations publication, Sales No. E.76.v.8), draft Part III, Article 48. 
As noted above, in 1977, the definition of MSR was ultimately omitted altogether from UNCLOS. Nevertheless, Article 240(b) of the Convention requires that MSR "be conducted with appropriate scientific methods" and the Convention accords 'pure' scientific research a privileged position in the presumption that coastal states will normally consent to research carried out in their exclusive economic zones or on their continental shelves where it is for "peaceful purposes ... in order to increase scientific knowledge of the marine environment for the benefit of all mankind." 55 Post-unclos there has, until recently, been very little appetite to further develop a working definition of MSR. Even the International Court of Justice in the 2014 Whaling in the Antarctic Case declined to define scientific research notwithstanding the centrality of the notion to the dispute between Japan, Australia and New Zealand over Japanese so-called 'scientific' whaling activities. ${ }^{56}$

By contrast, the organisation to give most consideration to articulating the concept of MSR is the International Maritime Organisations (IMO) through the 1996 Protocol to the 1972 London Convention in the context of geoengineering itself. As will be discussed below, the parties to the Protocol have agreed to use the Protocol to regulate marine geoengineering activities, which is defined for the purpose of the Protocol as "a deliberate intervention in the marine environment to manipulate natural processes, including to counteract anthropogenic climate change and/or its impacts, and that has the potential to result in deleterious effects, especially where those effects may be widespread, long lasting or severe. ${ }^{57}$ Geoengineering activities listed in the new Annex 4 to the Protocol are prohibited unless expressly permitted and authorised by a permit. ${ }^{58}$ Currently the only permitted activity listed in Annex 4 is ocean fertilization ${ }^{59}$ for legitimate scientific research. ${ }^{60}$ Whilst 'legitimate scientific research' is not expressly defined in the Protocol, the Risk Assessment Framework, which is designed to guide the issue of permits, sets out a non-exhaustive list of the purposes of such research: to better understand the natural processes associated

$55 \quad 1982$ UnCLOS, Article 246(3).

56 Whaling in the Antarctic (Australia v. Japan: New Zealand Intervening) [2014] ICJ Rep. 226 at para. 86 .

571996 Protocol to the 1972 London Convention, Article 5 bis (not yet in force).

$5^{8}$ Ibid., Article 6bis (not yet in force).

59 Ocean fertilization for the purposes of Annex 4 is defined as "any activity undertaken by humans with the principal intention of stimulating primary productivity in the oceans. Ocean fertilization does not include conventional aquaculture, or mariculture, or the creation of artificial reefs." (Annex 4, Article 1(1) (not yet in force).

6o 1996 Protocol to the 1972 London Convention, Annex 4, Article 1(3) (not yet in force). 
with geoengineering; to understand the potential impact of geoengineering on the marine environment; and to understand the extent to which geoengineering may be an effective climate change mitigation measure. ${ }^{61}$ The Framework, which has been incorporated into a new Annex 5 of the Protocol, further sets out a range of factors that are integral to how 'legitimate scientific research' is described for the purpose of the Protocol:62

- the proposed activity is designed to answer questions that will add to scientific knowledge. Proposals should state their rationale, research goals, scientific hypotheses and methods, scale, timings, duration and locations with clear justification for why the expected outcomes cannot reasonably be achieved by other methods.

- the research methodology to be applied should be appropriate and based on best available scientific knowledge and technology. The methodology should be described in sufficient detail to allow a peer review.

- the proposed activity is subject to scientific peer review at appropriate stages in the assessment process.

- economic interests do not influence the design, conduct and/or outcomes of the proposed activity. There should not be any financial and/or economic gain arising directly from the experiment or its outcomes. This does not preclude payment for services rendered in support of the experiment or future financial impacts of patented technology.

- the proponents of the proposed activity make a commitment to publish the results in peer reviewed scientific publications and include a plan in the proposal to make the data and outcomes publicly available in an appropriate and specified time-frame.

- the proposed activity has the financial resources available before the work commences to fulfil the program of work.

This description does not distinguish between pure and applied scientific research per se but it emphasises its purpose, which is to add to scientific knowledge, and stipulates that it must not lead directly to financial or economic gain. It emphasises the importance of scientific methods including peer review and publication.

$61 \quad$ Ibid., Annex 5, paragraph 7 (not yet in force). 
As noted above, MSR was officially recognised as a freedom of the high seas by UNCLOS. ${ }^{64}$ The Convention establishes a permissive regime regulating MSR whereby research is permitted subject to a number of broad principles set out under the Convention and limited coastal state control. In particular, all MSR should be conducted for exclusively peaceful purposes, use appropriate scientific methods, refrain from unjustifiable interference with other uses of the seas ${ }^{65}$ comply with other provisions of UNCLOS including those designed to protect the marine environment, ${ }^{66}$ to manage the Area, ${ }^{67}$ and to promote cooperation and the dissemination of information and knowledge. ${ }^{68}$ In light of the environmental risks posed by geoengineering activities deliberately designed to manipulate ocean processes and ecosystems, it is the environmental constraints under Part XII of the Convention-which, owing to space constraints are not discussed in detail in this chapter ${ }^{69}$ — that are of particular relevance to geoengineering-related MSR, especially in areas beyond national jurisdiction. However, the relatively high threshold for harm and definition of pollution under UNCLOS, ${ }^{70}$ in practice, limits the impact of these provisions on small scale scientific research.

In areas under the jurisdiction of states MSR remains under the exclusive jurisdiction of the coastal state ${ }^{71}$ although where permission is sought to conduct research a coastal state is normally expected to consent to requests to carry out research in its $\mathrm{EEZ}$, particularly where that research is intended to "increase scientific knowledge of the marine environment for the benefit of all mankind." ${ }^{2}$ It is worth noting that consent may nevertheless be withheld

63 See generally, Tim Stephens and Donald R Rothwell, 'Marine Scientific Research' in Donald R. Rothwell, Alex G. Oude Elferink, Karen N. Scott and Tim Stephens (eds.), The Oxford Handbook of the Law of the Sea (Oxford University Press, 2015), 559.

641982 UNCLOS, Article 87(1)(f) and 238.

65 Ibid., Article 240.

66 Ibid., Article 240 (d).

67 Ibid., Article 256.

68 Ibid., Articles 242 and 244.

69 See however, Karen N. Scott, 'Geoengineering and the Law of the Sea' in Rosemary Rayfuse (ed.), Research Handbook on International Marine Environmental Law (Edward Elgar Publishing, 2015), $45^{1}$ and Karen N. Scott, 'International Law in the Anthropocene: Responding to the Geoengineering Challenge' 34 (2013), Michigan Journal of International Law 309.

70 Set out in Article 1(4) of the 1982 UnCLOS.

711982 UnClOs, Articles 56(1)(b)(ii), 245 and 246.

$72 \quad 1982$ UnCLOS Article 246(3). 
where the research involves the introduction of harmful substances into the marine environment, ${ }^{73}$ which arguably would include iron or other nutrients associated with ocean fertilization.

Control of geoengineering-related scientific research under UNCLOS is therefore relatively light and it is unsurprising that other instruments provide direct or indirect regulation at a level that is more robust. Provided those other instruments do not create rights and obligations that are incompatible with UNCLOS or do not affect the enjoyment of UNCLOS rights by other parties to the Convention, those instruments may be applied alongside UNCLOS. ${ }^{74}$ Moreover, UNCLOS expressly permits states to conclude agreements modifying UNCLOS provided that such agreements do not affect the application of the basic principles under the Convention or the basic rights and obligations of states party to UNCLOS. ${ }^{75}$ The two instruments of primary application to geoengineering-related MSR in ABNJ are the 1996 Protocol to the 1972 Convention and the 1991 Protocol to the 1959 Antarctic Treaty. The provisions of both instruments are compatible with, and therefore should be applied alongside, UNCLOS.

An interesting question is whether ultimately, the provisions of the 1996 Protocol can actually be applied under UNCLOS itself. Article 210 of UNCLOS regulates dumping at sea and requires that national laws, regulations and measures are no less effective than "global rules and standards." ${ }^{\text {" }}$ It is widely recognised that those global rules and standards refer to the 1972 London Convention ${ }^{77}$ and UNCLOS currently lacks a mechanism for determining if and at what stage the 1996 Protocol replaces the Convention as providing those "global rules and standards". The Protocol thus far is supported by about half the number of states which have ratified the 1972 Convention and it would therefore seem premature to interpret Article 210(6) as referring to the Protocol rather than to the Convention. Moreover, the amendments to the Protocol, which create the regime for regulating geoengineering, are not yet in force. More fundamentally, Article 210 specifically refers to "dumping" which is defined in Article 1(5) of UNCLOS as the deliberate disposal of waste or other matter at sea and which explicitly excludes "placement of matter for a purpose other than the mere disposal thereof, provided that such placement is not contrary to the aims of

\footnotetext{
73 Ibid., Article 245(5)(b).

74 Ibid., Article 311(2).

75 Ibid., Article 311(3).

76 Ibid., Article $210(6)$.

77 R. R. Churchill and A. V. Lowe, The Law of the Sea, 3rd edn. (Manchester University Press 1999), 369 .
} 
the Convention."78 Geoengineering for legitimate scientific purposes is categorised as placement rather than dumping and therefore arguably falls outside the scope of Article 210 of UNCLOS. On this basis, it is unclear whether the rules and standards relating to geoengineering authorised by the 1996 Protocol can be categorised as "global rules and standards" for the purposes of Article 210 of UNCLOS.

\section{5}

Geoengineering MSR under the 1996 London Protocol (as Amended)

As briefly described above, the 53 parties of the 1996 Protocol to the 1972 London Convention amended the Protocol in October 2013 in order to create a legal basis for the regulation of marine geoengineering. ${ }^{79}$ The definition of geoengineering as set out above ${ }^{80}$ is broad and arguably expands the aims and objectives of the Protocol in that it covers activities that do not constitute the abandonment, disposal or placement of matter in the oceans. Nevertheless, currently the scope of the regulatory framework for geoengineering is confined to activities involving the introduction of matter into the sea. Article 6bis (not yet in force) stipulates that Contracting Parties "shall not allow the placement of matter into the sea from vessels, aircraft, platforms, or other man-made structures at sea for marine geo-engineering activities listed in annex 4, unless the listing provides that the activity or the sub-category of an activity may be authorised under a permit." 81 The only activity listed in Annex 4 that may be authorised subject to a permit is ocean fertilization "constituting legitimate scientific research." ${ }^{\prime 2}$ Both Article 6bis and Annex 4 of the Protocol require parties to comply with the detailed Risk Assessment Framework set out in Annex 5 of the Protocol.

The Risk Assessment Framework, which was adopted in a non-binding resolution in 2010,83 and adapted with minor amendments for inclusion within a new Annex 5 of the Protocol, sets out the most detailed international

\footnotetext{
$78 \quad 1982$ UnClos, Article 1(5)(b)(ii).

79 Resolution LP.4(8) On the Amendment to the London Protocol to Regulate the Placement of Matterfor Ocean Fertilization and other Marine Geoengineering Activities (18 October 2013).

8o See text at footnote 57 .

81 Article 6bis (1) of the amended Protocol (amendment not yet in force).

82 Annex 4.1, 1996 Protocol as amended (amendment and Annex not yet in force).

83 Resolution LC.LP.2 (2010) On the Assessment Framework for Scientific Research Involving Ocean Fertilization.
} 
assessment criteria relating to marine scientific research of any instrument to date. The Framework sets out a two-stage process whereby first, the proposed activity is assessed in order to ascertain whether it constitutes legitimate scientific research (and thereby complies with the criteria set out in Annex 4 of the Protocol) and second, assessed in order to determine that pollution of the marine environment is, as far as practicable, prevented or reduced to a minimum. The initial assessment focuses on the nature and purpose of the activity with a strong emphasis on scientific method. ${ }^{84}$ These criteria were discussed above in the context of defining the term 'marine scientific research'. ${ }^{85}$ Once a proposed activity is categorised as legitimate scientific research it is subject to a full environmental impact assessment, including an examination of the site selected for the experiment and the matter intended to be placed into the environment. ${ }^{86}$ Parties are required to develop an "Impact Hypothesis", which is a statement of the expected consequences of the placement as well as the other potential impacts including transboundary effects. ${ }^{87}$ Factors expressly identified for consideration include potential impacts on human health, on marine ecosystems, amenities and other uses of the sea as well as cumulative impacts. ${ }^{88}$ Parties must also consider the risks of accidents, economic factors and exclusion of future uses. ${ }^{89}$ The Risk Assessment Framework endorses an explicitly precautionary approach ${ }^{90}$ and requires parties to minimise environmental risks through mitigation, contingency planning ${ }^{91}$ as well as monitoring. ${ }^{92}$ Most significantly "if the assessment reveals that adequate information is not available to determine the likely effects of the proposed placement activity then this activity shall not be considered further." ${ }^{\prime 3}$ Finally, the Framework requires parties to consult and cooperate with other states or international organisations which may be affected by the research activities. ${ }^{94}$ Furthermore, the Framework establishes a procedure for consultation with national and international stakeholders and to consider any advice provided by independent international experts or independent international advisory groups. ${ }^{95}$

\footnotetext{
841996 London Protocol, Annex 5, paragraphs 4-9 (not yet in force).

85 Discussed above in Part 4 of this chapter.

861996 London Protocol, Annex 5, paragraphs 14-15 (not yet in force).

87 Ibid., paragraph 16 (not yet in force).

88 Ibid., paragraph 17 (not yet in force).

89 Ibid., paragraph 18 (not yet in force).

90 Ibid., paragraph 20 (not yet in force).

91 Ibid., paragraphs 20-22 (not yet in force).

92 Ibid., paragraphs $23-25$ (not yet in force).

93 Ibid., paragraph 18 (emphasis added) (not yet in force).

94 Ibid., paragraph 10 (not yet in force).

95 Ibid., paragraphs 11 and 12 (not yet in force).
} 
Once the assessment has been completed, its outcome must be reported to the Protocol Secretariat and be made publicly available. ${ }^{96}$ Where a state has failed to comply with the conditions of Annexes 4 or 5 of the Protocol, the matter may be referred to the Protocol Compliance Group, which was formally established in 2007 pursuant to Article 11 of the Protocol. ${ }^{97}$ The Compliance Group has the power to make recommendations to support the state bringing its conduct into compliance with the Protocol. Currently, specific procedures relating to liability for environmental damage resulting from dumping or incineration at sea have yet to be developed under the Protocol, and it is worth noting that Article 15 of the Protocol as it stands refers to liability in respect of dumping or incineration at sea and not to other activities such as MSR or placement. ${ }^{98}$ General rules of state responsibility in respect of environmental damage are of course applicable as a matter of international law.

In summary, the emerging regulatory regime for marine geoengineering under the 1996 London Protocol is robust, precautionary and supportive of international collaboration and consultation. Nevertheless, its scope is currently limited. The amendments to the Protocol are not yet in force (only five states have ratified the amendments: Estonia, Finland, Netherlands, Norway and the United Kingdom) and the Protocol itself currently binds only 53 states. Moreover, notwithstanding the broad definition of geoengineering in the Protocol, its scope is presently limited to activities involving the placement of matter on or into the marine environment.

\section{Geoengineering MSR under the 1991 Protocol to the 1959 Antarctic Treaty}

The Southern Ocean provides a promising environment for ocean fertilization research and deployment. In light of this, the majority of the experiments which have taken place to date have been located in the Southern Ocean. ${ }^{99}$

96 Ibid., paragraph 30 (not yet in force).

97 See the Report of the 29th Meeting of the 1972 London Convention LC29/17, Annex 7.

98 Article 15 of the 1996 Protocol stipulates that "[i]n accordance with the principles of international law regarding State responsibility for damage to the environment of other States or to any other area of the environment, the Contracting Parties undertake to develop procedures regarding liability arising from the dumping or incineration of wastes or other matter."

99 See Secretariat of the Convention on Biological Diversity, Scientific Synthesis Report on the Impacts of Ocean Fertilization on Marine Biodiversity (Technical Series No. 45) (Montreal: Secretariat of the Convention on Biological Diversity, 2009), at 24. 
Whilst the Southern Ocean is not governed by a typical regional seas regime, the area south of $60^{\circ}$ Latitude-which largely comprises ABNJ-is subject to the 1959 Antarctic Treaty and the 1991 Environmental Protocol to the Antarctic Treaty. Scientific research occupies a privileged position under the 1959 Treaty, ${ }^{100}$ but is nevertheless subject to controls under both the Treaty and the Protocol relating to cooperation and, most significantly, environmental protection. ${ }^{101}$ Much debate has been had over the years as to the extent to which the Treaty applies to the marine environment south of $60^{\circ}$ Latitude but, notwithstanding the reservation that "nothing in the present Treaty shall prejudice or in any way affect the rights, or the exercise of the rights, of any state under international law with regard to the high seas within that area" under Article VI of the Treaty, the practice of parties has been to restrict and manage those high seas rights, including the rights relating to MSR, ${ }^{102}$ which, it should be noted, are not formally defined under the Treaty. To date, all ocean fertilization experiments have taken place north of the Antarctic Treaty area and therefore arguably fall outside of the Treaty/Protocol requirements. However, the scope of the 1991 Environmental Protocol extends to not only the Antarctic Treaty area but also its "dependent and associated ecosystems".103 Therefore this scope has the potential to include activities outside of the Antarctic Treaty area which may impact directly or indirectly on the Antarctic ecosystem. In light of the uncertainties associated with the impacts of ocean fertilization and the ostensible purpose of the activity to deliberately alter natural ocean ecosystems it is appropriate to consider the application of the 1991 Protocol to such research activities.

The protection of the Antarctic environment has emerged as a key objective of the Antarctic Treaty system. Article 3(1) of the 1991 Environmental Protocol stipulates:

... the protection of the Antarctic environment and dependent and associated ecosystems and the intrinsic value of Antarctica, including its wilderness and aesthetic values and its value as an area for the conduct of

\footnotetext{
1001959 Antarctic Treaty, Articles II and III.

101 On science under the Treaty see generally Karen N. Scott, 'Scientific rhetoric and Antarctic security' in Alan D. Hemmings, Donald R. Rothwell and Karen N. Scott (eds.), Antarctic Security in the Twenty-First Century (Routledge, 2012), 284.

102 See Karen N. Scott and David L VanderZwaag, 'Polar Oceans and the Law of the Sea' in Donald R Rothwell, Alex G. Oude Elferink, Karen N. Scott and Tim Stephens (eds.), The Oxford Handbook of the Law of the Sea (ou P 2015), 724 at 741-742.

1031991 Environmental Protocol, Articles 2, 3 and 8.
} 
scientific research, in particular research essential to the understanding of the global environment, shall be fundamental considerations in the planning and conduct of all activities in the Antarctic Treaty area.

Planning and environmental impact assessment is the core tool for environmental protection in the Antarctic, and Article 8 of the Protocol requires all activities subject to the advance notification requirement as set out in Article VII(5) of the Antarctic Treaty-including all expeditions to and within Antarctica-to prepare an environmental impact assessment where that activity is likely to have a minor or transitory impact on the Antarctic environment or its dependent and associated ecosystems.

Annex I of the Protocol sets out the environmental impact assessment requirements in detail, distinguishing between activities likely to have only a minor or transitory impact and activities likely to have more than a minor or transitory impact. In the case of the former, activities must undergo an initial environmental evaluation (IEE), which requires parties to describe the proposed activity and consider impacts, including cumulative impacts in light of existing and known planned activities. ${ }^{104}$ Parties must consider alternatives to the proposed activity ${ }^{105}$ and, if the activity goes ahead, must put in place appropriate contingency and monitoring procedures. ${ }^{106}$ In contrast to the requirements under the 1996 London Protocol, there is no express obligation to consult with other parties or to seek expert advice on the proposed activity. Initial environmental evaluations are carried out at the state level and are not required to be assessed at the international level by the Committee on Environmental Protection ${ }^{107}$ or the Antarctic Treaty Consultative Meeting (АТCM).108 By contrast, activities likely to have more than a minor or transitory impact on the Antarctic environment are subject to a Comprehensive Environmental Evaluation (CEE) and draft CEE reports must be made publically available and circulated to all parties for discussion at the Атсм. ${ }^{109}$ The range of factors that must be considered by parties is extensive and includes potential impacts, knowledge gaps and the identification of measures that may minimise

\footnotetext{
1041991 Environmental Protocol, Annex I, Article 2(1).

105 Ibid., Article 2(1)(b).

106 Ibid., Article 2(2).

107 The Committee on Environmental Protection was established under Article 11 of the 1991 Environmental Protocol.

108 The Antarctic Treaty Consultative Meeting was established under Article IX of the 1959 Antarctic Treaty.

1091 Environmental Protocol, Annex I, Articles 3-5.
} 
or mitigate impacts or support monitoring. ${ }^{110}$ Although parties must address comments received in relation to a draft CEE in the final CEE, ${ }^{111}$ the ATCM is given no formal power to prevent an activity from taking place or to attach conditions to that activity.

In contrast to the 1996 Protocol to the 1972 Convention, the 1991 Environmental Protocol does not provide for a formal non-compliance mechanism, although matters of non-compliance can be raised at the annual Antarctic Treaty Consultative Meeting. ${ }^{112}$ However, the 1959 Antarctic Treaty and 1991 Environmental Protocol provide for an international system of inspection, and permit research vessels to be inspected within the Antarctic Treaty Area. ${ }^{113}$ The Protocol has developed reasonably sophisticated provisions relating to monitoring and contingency planning ${ }^{114}$ and has established a liability regime applicable to operators responsible for environmental damage within the Antarctic Treaty Area. ${ }^{115}$ The liability regime, however, has not yet entered into force.

In summary, the regulatory regime for MSR under the 1991 Environmental Protocol is environmentally robust and complements the obligations under the 1959 Antarctic Treaty relating to collaboration and free dissemination of research findings. ${ }^{116}$ However, the terms "minor" and "transitory" are not defined under the Protocol and it is the state concerned which determines whether an IEE or CEE is required in relation to any particular activity. Notably only one ocean fertilization experiment has been subject to the IEE process. ${ }^{117}$ Moreover, international oversight and ultimate control of environmental impact assessments is limited and the requirements relating to consultation and peer review are noticeably weaker than those provided under the 1996 Protocol. As a regional regime, the Protocol currently binds only 40 states although its provisions, in contrast to the 1996 Protocol, are in force. Its greatest limitation however, is its geographical scope, which is confined to south of $60^{\circ}$ south Latitude. Although the 1991 Protocol refers on numerous occasions to "dependent and associated ecosystems", and there has been discussion in the past about

\footnotetext{
110 Ibid., Article 3(2).

111 Ibid., Article 3(6).

1121991 Environmental Protocol, Article 13.

1131959 Antarctic Treaty, Article ViI(1)-(4); 1991 Environmental Protocol, Article 14.

114 In particular within Annex VI to the Protocol (not yet in force).

1151991 Environmental Protocol, Annex Vi (not yet in force).

1161959 Antarctic Treaty, Articles II and III.

117 An IEE was carried out by New Zealand in 1998 in respect of the voyage of the Tangarora in 1999, which supported research into the impact of iron on phytoplankton growth.
} 
extending its remit to include the entire Antarctic ecosystem, ${ }^{118}$ the practice of states thus far has been to confine its regulatory scope to activities taking place within the Antarctic Treaty area.

\section{7}

\section{Concluding Remarks}

Both the 1996 Protocol to the 1972 London Convention and the 1991 Environmental Protocol to the 1959 Antarctic Treaty establish relatively robust regimes designed to protect the environment from damaging MSR associated with geoengineering. Annex 5 of the 1996 Protocol builds on the 1991 Environmental Protocol which, until 2013, arguably provided the most precautionary regulatory regime of application to MSR. However, the Risk Assessment Framework incorporated in Annex 5 of the 1996 Protocol goes beyond the 1991 Protocol in its provisions relating to consultation and its express endorsement of the precautionary approach. Nevertheless, in practical terms both regimes are significantly limited in scope: the 1991 Protocol applies exclusively to the Antarctic Treaty area and the amendments to the 1996 Protocol are not yet in force. More fundamentally however, neither regime has attempted to engage with the broader ethical issues associated with geoengineering related to scientific research, focusing instead on managing the potential environmental impacts of such activities. This is a significant lacuna and demonstrates the limitations of both regimes to address the ultimate question of whether we should manipulate ocean processes in order to mitigate climate change and how we manage the relationship between geoengineering and other mitigation measures, including emissions reductions as well as the broader ethical issues arising from geoengineering. ${ }^{119}$

It is uncertain at this stage as to whether and to what extent the BBNJ Agreement may also apply to geoengineering MSR and constitute a 'potential solution' to some of the gaps and other issues identified above. MSR is not defined in the draft text although 'marine technology' is. ${ }^{120}$ Much of the text relating to environmental impact assessment in the draft due to be debated at the third negotiating session in March 2020 remains in square brackets, and currently there is little consensus on important issues such as the threshold for assessment and the relationship between the вBNJ Agreement and other instruments. The threshold

118 See for example, Resolution 1 Enhancement of Environmental Protection up to the Antarctic Convergence (17 April 2009).

119 These issues are explored more fully in Karen N. Scott, op. cit. n. 46.

120 ввNJ March 2020 Draft Text, op. cit. n 2, Art 1 [11]. 
for an EIA ranges from 'minor and transitory', 21 which arguably would be triggered by geoengineering MSR to 'substantial pollution' or 'significant and harmful changes' 122 which would likely not be reached in respect of geoengineering for research purposes only. The relationship between the BBNJ Agreement and existing regimes that provide for EIA is similarly uncertain, with options ranging from no EIA where one is required by another body to mandating that all EIAs, including those under other regimes, meet the substantive requirements set out in the Agreement. ${ }^{123}$ The Agreement, like the 1996 London Protocol and 1991 Environmental Protocol to the Antarctic Treaty, will not address the ethics of geoengineering but, notably, it is proposed that parties to the BBNJ Agreement be guided by "[a]n approach that builds ecosystem resilience to the adverse effects of climate change and ocean acidification and restores ecosystem integrity.'124 It might be argued that at least some forms of geoengineering research, particularly ocean fertilization which increases carbon dioxide levels in the oceans, could be regarded as being contrary to this principle.

Nevetheless, what this case study on geoengineering MSR demonstrates is that the ввол Agreement is unlikely to be a pancea with respect to managing the environmental effects of activities taking place beyond the jurisdiction of states. Existing instruments remain important and need to be supported by states and by international organisations. With respect to geoengineering MSR in ABNJ, the challenge is far from intractable and the most important solution is the ratification and, thus, entry into force of the 2013 amendments to the 1996 London Protocol.

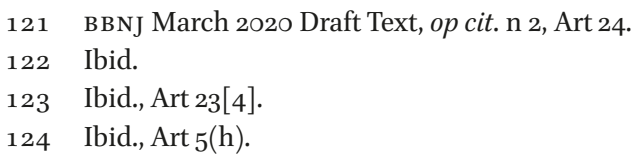


Karen N. Scott - 9789004422438

Downloaded from Brill.com $04 / 26 / 2023$ 09:33:59AM via free access 